\title{
Popular approval of Covid-19 restrictions is strongly correlated with vaccination rate
}

Jean-Luc Jucker ( $\nabla$ jeanluc.jucker@gmail.com )

https://orcid.org/0000-0001-5046-1145

\section{Short Report}

Keywords: COVID-19, public health, vaccination, elections and voting behavior, Switzerland, referendum, correlation

Posted Date: February 24th, 2022

DOI: https://doi.org/10.21203/rs.3.rs-1386561/v1

License: (c) (i) This work is licensed under a Creative Commons Attribution 4.0 International License. Read Full License 


\section{Abstract}

Most governments in the world have implemented restrictive measures to fight against the Covid-19 pandemic. Little is known, however, on people's approval or disapproval of these restrictions, and importantly, on the factors that might contribute to approval. Switzerland might be the only country where citizens voted on Covid-19 restrictive measures by referendum, thereby providing a rare opportunity to assess the extent to which people approve Covid-19 restrictions. Using data from the Swiss authorities, we find that the percentage of people who approved Covid-19 restrictions by vote strongly positively correlates with the percentage of people vaccinated in the population $(r=0.929, p<0.0001)$. This suggests that vaccinated people are more likely to approve Covid-19 restrictions, which raises interesting questions for further research.

\section{Full Text}

Most governments in the world have implemented restrictive measures to fight against the Covid-19 pandemic, such as quarantines, travel limitations, school closures, vaccination certificates, etc. ${ }^{1,2}$ Little is known, however, on people's approval or disapproval of these restrictions, and importantly, on the factors that might contribute to approval. This is an important limitation since compliance with governmental restrictions is arguably key in preventing the spread of the Covid-19 pandemic.

Switzerland might be the only country where citizens voted (two times as of today) on Covid-19 restrictive measures by referendum ${ }^{3}$, thereby providing a rare opportunity to assess the extent to which people approve Covid-19 restrictions. In particular, the second referendum of 28 November 2021, which concerned, amongst others, the introduction of a vaccination certificate, was highly debated in Switzerland. It might therefore be used as an indicator of people's degree of approval related to Covid-19 measures perceived as controversial.

The referendum of 28 November 2021 was accepted by $62.02 \%(n=2,222,373)$ of all registered voters, and in all the 26 cantons of Switzerland except in Schwytz (48.61\% of yes) and Appenzell Innerrhoden (44.21\% of yes), thereby showing that a majority of Swiss citizens support Covid-19 related measures. Furthermore, using data made publicly available by the Swiss Federal Statistical Office and Federal Office of Public Health ${ }^{4,5}$, it is possible to investigate relationships between the outcome of this referendum and Covid-19 population variables, notably vaccination rate ${ }^{6}$, which was $65.85 \%$ of the population at the time of the referendum. In other words, it is possible to compute correlations between the percentage of voters who accepted the referendum and the percentage of people vaccinated in the population, and this across the 26 cantons. Doing this, we find that the percentage of people vaccinated strongly positively correlates with the percentage of people who approved the object of the referendum $(r=0.929, p<0.0001$, Fig. 1$)$. In other words, the higher the vaccination rate, the higher the acceptance of the referendum and related Covid-19 measures. 
Specifically, we find that an increase of 1 point of percentage in vaccinated persons is associated with an increase of 1.46 point of percentage in approval of the referendum $\left(95 \% \mathrm{Cl}=1.22\right.$ to $\left.1.71, R^{2}=0.863\right)$. We note that introducing population size $\mathrm{e}^{7}$ and number of registered voters as control variables in regression analysis does not significantly change the results. Likewise, no significant relationships were found when the number of Covid-19 related hospitalizations or deaths were used as predictor instead of the percentage of people vaccinated.

The observed relationship demonstrates that popular approval or disapproval of Covid-19 restrictive measures might be strongly related to vaccination rate, with populations more vaccinated also more likely to support such measures. This might be explained by a range of factors (political, cultural, individual, psychological), which would be worth to explore in dedicated research.

First, there might simply be an adequation between vaccination behavior and voting behavior, one reflecting the other. This would not be surprising if we consider that vaccination is itself a measure to fight the spread of the pandemic. Hence people who are vaccinated should also be, on average, more likely to accept other (or more extended) measures. Second, both vaccination behavior and voting behavior might partly reflect political affiliation. In Switzerland, political parties make voting recommendations to their members for each referendum. For the referendum of 28 November 2021, all major political parties, except the Swiss People's Party (SVP), recommended to vote yes. Taken together, the political parties who recommended to vote yes represent roughly 60 to $70 \%$ of all seats at the National Council (i.e., the lower house of the Federal Assembly). This figure is similar to the percentage of people who accepted the referendum (62.02\%), and to the percentage of people who were vaccinated in the population at the same time (65.85\%). Third, the close relationship between vaccination rate and approval of Covid-19 measures might also be partly explained by cognitive dissonance dynamics. For example, we might consider that although people who are vaccinated are not necessarily approving more (or more extended) measures, they voted yes to maintain adequation between their vaccination behavior and opinions (reflected in voting behavior) concerning the best strategies to prevent the spread of the Covid-19 pandemic. We believe that this, however, is not likely.

The above are only possible explanations, and we cannot, of course, generalize the findings presented above to other countries or populations. For example, the range and stringency of governmental measures might also have an impact on popular approval. From this point of view, the Swiss government implemented less, and less restrictive measures than its neighbors (see a comparison over time here: https://tinyurl.com/t9ywkunc), which might have an influence on both vaccination rate and voting outcome. Finally, the Covid-19 incidence and related hospitalizations and deaths might, of course, have an impact on popular approval of restrictive measures, with countries more impacted by the Covid-19 arguably more likely to approve more restrictive measures. That said, the current finding shows for the first time that popular approval of Covid-19 related measures can strongly correlate with vaccinate rate in the population, as one factors amongst others that might explain compliance.

\section{Declarations}


The author declares that no funds, grants, or other support were received during the preparation of this manuscript. The author has no relevant financial or non-financial interests to disclose. The author is the only contributor of this manuscript. Ethics approval: not applicable. Consent to participate: not applicable. Consent to publish: not applicable.

\section{References}

1. Hale T, Angrist N, Goldszmidt R, et al. A global panel database of pandemic policies (Oxford COVID19 Government Response Tracker). Nature Human Behaviour. 2021;5(4):529-38. doi: https://doi.org/10.1038/s41562-021-01079-8

2. European Centre for Disease Prevention and Control (ECDC). Data on country response measures to COVID-19. 2022. https://www.ecdc.europa.eu/en/publications-data/download-data-responsemeasures-covid-19 (accessed Jan 24, 2022).

3. Francetic I. Bad law or implementation flaws? Lessons from the implementation of the new law on epidemics during the response to the first wave of COVID-19 in Switzerland. Health Policy. 2021; 125(10):1285-90. doi: https://doi.org/10.1016/j.healthpol.2021.08.004

4. Federal Office of Public Health FOPH. COVID-19 Switzerland Dashboard. 2022. https://www.covid19.admin.ch/en/overview (accessed Jan 24, 2022).

5. Swiss Confederation: Swiss Chancellery. Popular Votations. 2022. https://www.bk.admin.ch/bk/fr/home/droits-politiques/votations-populaires.html (accessed Jan 24, 2022).

6. Jucker JL. COVID-19 vaccination is associated with decreasing cases, hospitalizations, and deaths across age groups and variants over 9 months in Switzerland. medRxiv. 2022. doi: https://doi.org/10.1101/2022.02.03.22270396

7. Björk J, Modig K, Kahn F, Ahlbom A. Revival of ecological studies during the COVID-19 pandemic. European Journal of Epidemiology. 2021;36,1225-1229. doi: https://doi.org/10.1007/s10654-02100830-9

\section{Figures}




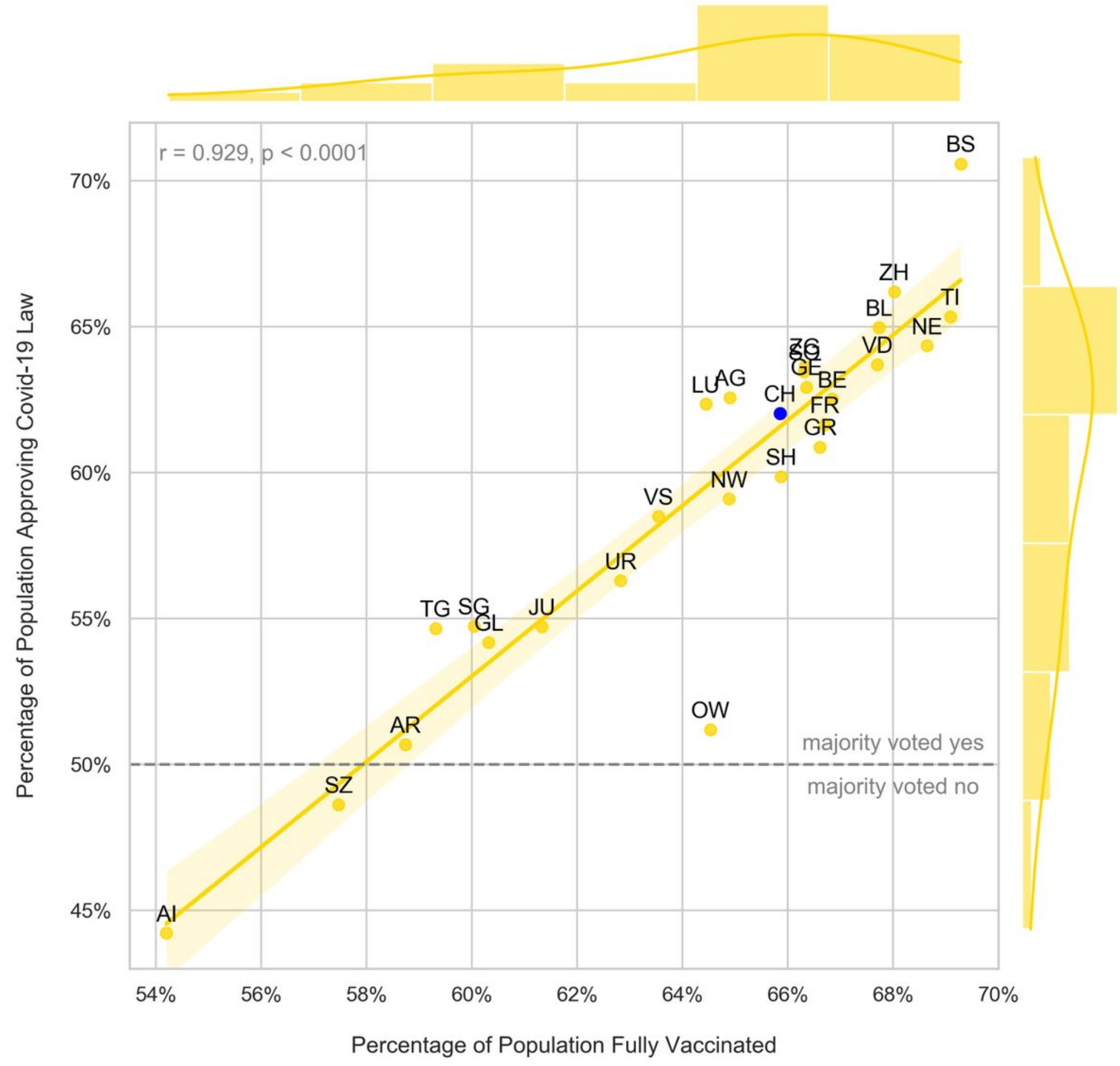

\section{Figure 1}

Relationship between percentage of population fully vaccinated and percentage of population approving the Covid-19 referendum of 28 November 2021. Each point represents one of the 26 cantons of Switzerland. Switzerland overall is labelled as $\mathrm{CH}$. The distribution of voting outcome and percent vaccinated is shown on the right and top of the figure, respectively. 